\title{
Selecting a Temporary Debris Management Site for Effective Debris Removal
}

\author{
Jooho Kim, Abhijeet Deshmukh, and Makarand Hastak \\ Construction Engineering and Management, School of Civil Engineering, Purdue University
}

\begin{abstract}
The overall debris removal after disasters is often prolonged due to the huge amount of debris and lack of capacities such as a Temporary Debris Management Site (TDMS) in the community. This results in a delay of overall recovery and increases the total recovery cost. Strategic planning and building a TDMS will help in providing extra time for proper disposal of debris and clearing a disaster-impacted site that will facilitate the reconstruction process.

This paper presents a unique approach for identifying and selecting TDMS locations for expediting debris removal from the community. A hypothetical example of a community impacted by a natural hazard is presented to explain how the the proposed model works. The research integrates data from a loss assessment report obtained from HAZUS-MH, Post Disaster Needs Assessment (PDNA), and Geographical Information System (GIS) in a dynamic simulation model. Various TDMS locations could be evaluated based on the existing capacity and infrastructure services and considering factors such as overall debris removal time, associated cost, productivity, and availability of resources. Debris management teams would greatly benefit from the research for strategically siting TDMS for accelerating the debris removal process.
\end{abstract}

\section{BACKGROUND AND NEEDS}

Recent research shows that the world is becoming vulnerable to extreme natural disasters such as hurricanes, floods, and earthquakes. These events often cause destruction to physical assets, such as buildings and infrastructure, resulting in the generation of a large volume of debris. Removal of debris in a timely manner can be challenging for communities as it may require capacities that exceed the existing capacities of the communities.

High impact disasters could result in generating five to ten times the debris volume of the annual waste generation rate of a community (Table 1).

Within limited capacities after disasters, the debris removal process is unable to be completed in the desired time which delays the response and recovery efforts of the community. In the United States, the debris removal process is undertaken in alliance with the city's waste management system.

There is a need to establish a system that is able to mesh well with the existing waste management system and bolster its capacities for expediting the debris process. This will allow the communities to handle the overwhelming amount of debris generated in the desired time. Both the Environmental Protection Agency (EPA) and Federal Emergency Management Agency (FEMA) have emphasized the need for temporary debris management sites (TDMS) for transporting and processing debris in a timely manner (EPA, 2008;
Table 1. Historical debris volume

\begin{tabular}{cccc}
\hline Year & Event & $\begin{array}{c}\text { Volume } \\
\text { (million CY) }\end{array}$ & Data \\
\hline 2012 & Hurricane Sandy & 5.25 & Elias, 2013 \\
2010 & Earthquake Haiti & $23-60$ & Booth, 2010 \\
2005 & Hurricane Katrina & 76 & Luther, 2006
\end{tabular}

FEMA, 2007). Additionally, it is very crucial to select the best locations for TDMS to avoid potential damage to the environment and community livelihoods. Channell et al. (2009) mentioned that there is more research to be carried out on the siting and management aspect of TMDS. This research proposes a framework that will allow the decision makers to select the best TDMS that will help in effectively removing the debris in a timely manner.

\section{OBJECTIVE}

This paper presents a TDMS selection model for effective debris removal. The main objectives of this paper are to:

- Identify a role of TDMS for debris removal operation

- Integrate geographical information from HAZUS-MH and Geographical Information System (GIS)

- Identify nonfeasible areas for TDMS and automate selection of feasible areas in a community by GIS 
- Develop a framework to select a suitable location of TDMS with geographical and optimization analysis

\section{LITERATURE REVIEW}

The objective of debris management in the past was to transfer debris from a community to the final destination as soon as possible. Thus, debris from disaster-affected areas was simply buried or burned. However, it caused air pollution from open burning and risks of contaminating drinking water and soil from uncontrolled burial (EPA, 1995). This produces economic and environmental issues in a long-term perspective (EPA, 2008).

\subsection{Current debris management}

Under normal circumstances, much municipal solid waste is recycled. The remainder is disposed of in sanitary landfills or in sophisticated combustors, both of which are equipped with devices to control pollutants. However, these standard waste disposal options are not sufficient to handle the tremendous amount of debris generated after a disaster. Further adding to the disposal dilemma is the fact that many municipalities are reluctant to overburden or deplete their existing disposal capacity with disaster debris.

Temporary debris management sites are established when a disaster-affected community is not able to take debris directly from the collection point to final destinations such as landfills and recycling facilities (FEMA, 2007). Additionally, the communities should develop debris management plans that include a detailed strategy for debris collection, temporary storage and staging areas, recycling, and disposal (United Nations Environment Programme [UNEP], 2008).

FEMA (2007) describes a sample layout for TDMS (Figure 1). TDMS includes grinders and air curtain incinerators to reduce the volume of debris as well as areas for hazardous wastes, construction, and demolition debris. One hundred acres of TDMS contains about 1 million CY debris.

Figure 2 describes the general process for debris removal (FEMA, 2007). After estimating the quantity of debris, collection activity starts hauling debris from debris collection sites to either debris management site or recycling sites. Then, the debris is hauled to final disposal areas (e.g., landfills and recycling sites).

\subsection{Advantages of TDMS}

Operating TDMS brings out several advantages. It provides a buffer to handle an overwhelming amount of debris by sorting and recycling the debris. In addition, TDMS reduces hauling time from collection points to the next station, that is, TDMS. It facilitates the beginning of other processes such as recovery and rebuilding (FEMA, 2007). In the Solid Waste Plan 2040 for the city of Lincoln, benefits of a transferring site are summarized as shown below (City of Lincoln, 2013):

- Control expenses

- Mitigate traffic at another site

- Control the flow of waste

- Provide user convenience (Public cost savings)

- Screen waste

- Facilitate recycling

- Improve the control of illegal dumping

- Help reduce air emissions

- Strategically control future waste management

\subsection{Issues for Locating a TDMS}

Even though it has various advantages for debris removal, it has several side effects. Basnayake, Chiemchaisri, and Visvanathan (2006) mentioned that an inappropriate location of TDMS can cause potential damage to the environment. For instance, in Kalmunai on the east coast of Sri Lanka, a playground in a low-lying area was used as a

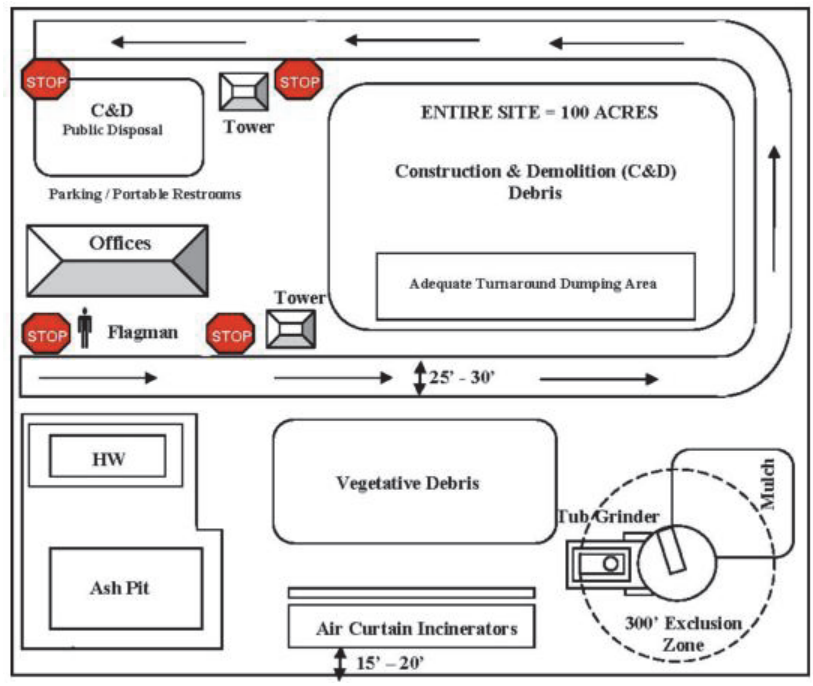

Figure 1. Sample layout for TDMS. Source: FEMA, 2007

Debris forecasts

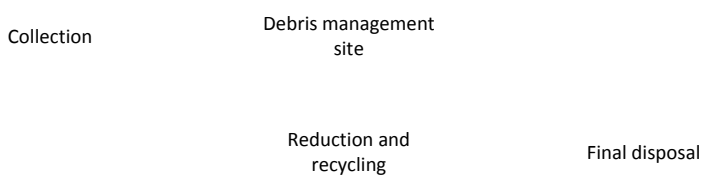

Figure 2. Debris management site component. Source: FEMA, 2007 
temporary debris disposal site. It resulted in leachate emissions polluting the wells near the playground and a considerable distance from it. Operating a TDMS might also require more expenses for debris removal and acquiring land for TDMS (FEMA, 2007).

Therefore, a decision maker should have an appropriate procedure and criteria for selecting a suitable TDMS. EPA (2008) provides some guidelines under "Protect Human Health and the Environment When Selecting Temporary Debris Management Sites" to recommend feasible areas for a TDMS:

- Be sufficient in size with appropriate topography and soil type

- Be located an appropriate distance from potable water wells and rivers, lakes, and streams

- Not be located in a floodplain or wetland

- Have controls in place to mitigate storm water runoff, erosion, fires, and dust

- Be free from obstructions, such as power lines and pipelines

- Have limited access with only certain areas open to the public, such as areas to drop off debris

- Be located close to the impacted area, but far enough away from residences, infrastructure, and businesses that could be affected by site operations

- Preferably be on public lands because approval for this use is generally easier to obtain, but could also be located on private lands. Private lands may be convenient and logistically necessary for temporary debris storage sites

\section{TDMS SELECTION MODEL}

To provide appropriate TDMS locations for a debris management team and minimize unexpected damages by improper locations of TDMS, this paper suggests a TDMS selection model (Figure 3 ).

The proposed TDMS selection model consists of two modules, geographical analysis and optimization analysis. After collecting all required geographical data, the proposed model generates feasible areas for TDMS by geographical analysis. The following step is to select an appropriate location for TDMS from the feasible areas by optimization analysis.

This paper assumed certain attributes to simulate the proposed TDMS selection model. Debris was generated by HAZUS-MH. Figure 4 shows a hypothetical community with debris generated.

\subsection{Geographical Analysis}

To start geographical analysis, the TDMS selection model requires certain data from a community. The required data is described below (Based on either a characteristic of a community or a decision maker, the criteria would be changed.).

- Topography

- Locations of debris generated

- Road network with current serviceability

- Debris handling facilities

- Residential area

- School, church, and hospital

- Wetlands

- 100 year flood area

- Historical area

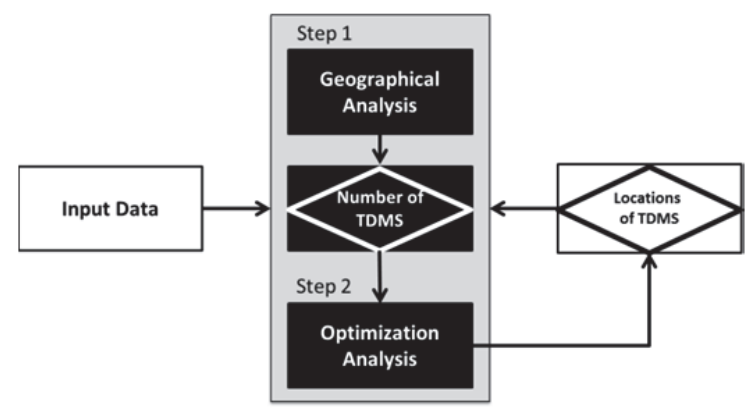

Figure 3. TDMS selection model

Table 2. List of attributes

\begin{tabular}{cc}
\hline List & Attributes \\
\hline Population & $2,500,000$ \\
Community size & $6,296 \mathrm{~km}^{2}$ \\
Disaster type & Hurricane $(10$ year event $)$ \\
Debris generated & 419,234 tons \\
Required TDMS & 1 \\
Road conditions & Not affected \\
\hline
\end{tabular}

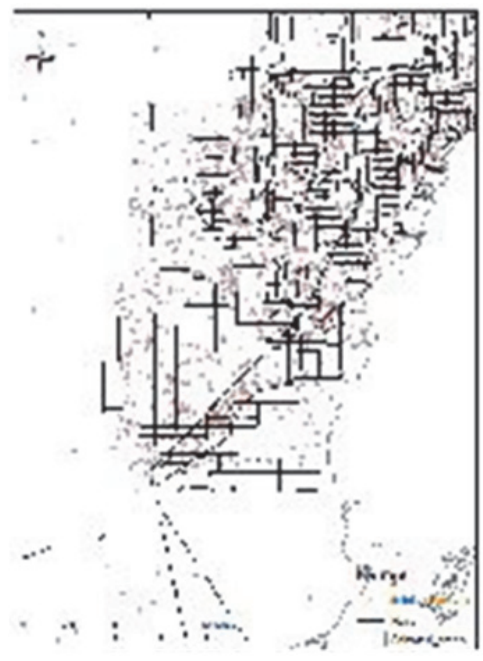

Figure 4. Hypothetical community 

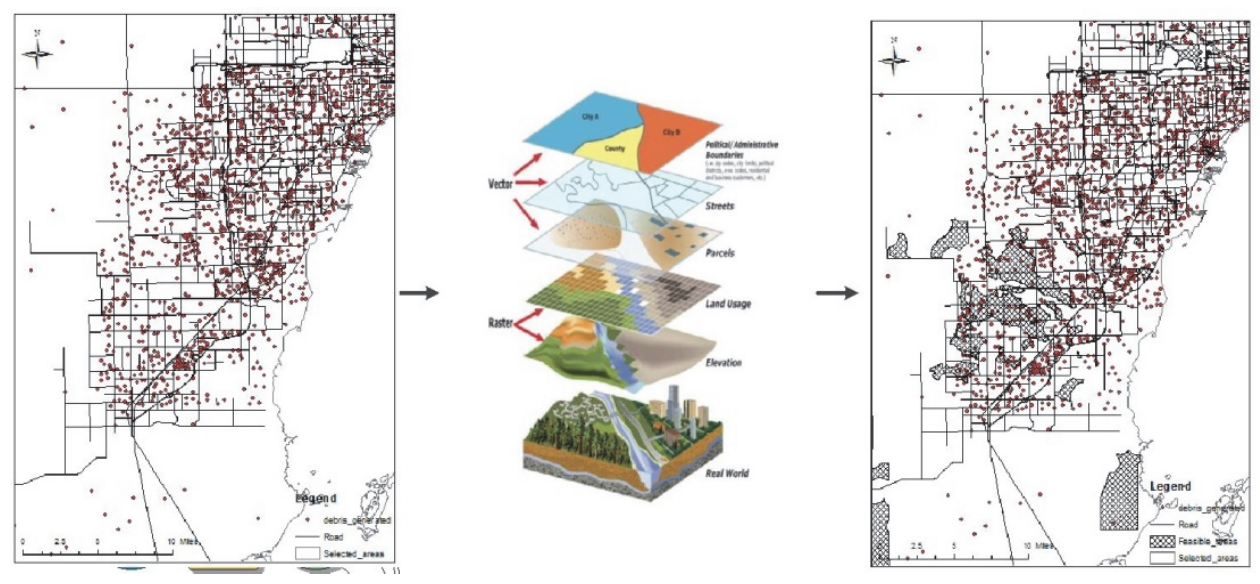

Figure 5. Geographical analysis in a TDMS selection model

The data above is input into GIS. It will combine all the data and generate a map of nonfeasible areas with a certain buffer. Finally, it subtracts the nonfeasible areas from a community. In Figure 5, it describes how feasible areas in a community are generated by GIS.

\subsection{Optimization analysis}

Most of the expense for debris removal is from hauling debris by equipment such as trucks, rail, or barges. Equation 1 shows an equation to calculate the productivity of construction equipment (Schaufelberger, 1999).

Within limited efficiency and capacity of construction equipment, cycle time is a critical factor to expedite the productivity above. To facilitate the productivity, a TDMS should be located to minimize total hauling distance from collection points to TDMS.

Optimization analysis is applied to select the best TDMS location which satisfies minimizing total hauling distance from collection points to TDMS (Equation 1).

$$
=\quad \sum
$$

\section{: : Location of TDMS candidate}

To select a suitable location of TDMS from feasible areas, this paper selects 26 TDMS candidates (Figure 6). Then, the optimization method in GIS compares total distance from each debris collection points to the TDMS candidates (Equation 3). Finally, it visualizes the best location that has a minimum total distance among the 26 TDMS candidates.

Distances from the selected TDMS to each debris collection points are automatically calculated by GIS. Figure 7 describes numbers of debris with certain miles based on the selected TDMS location.

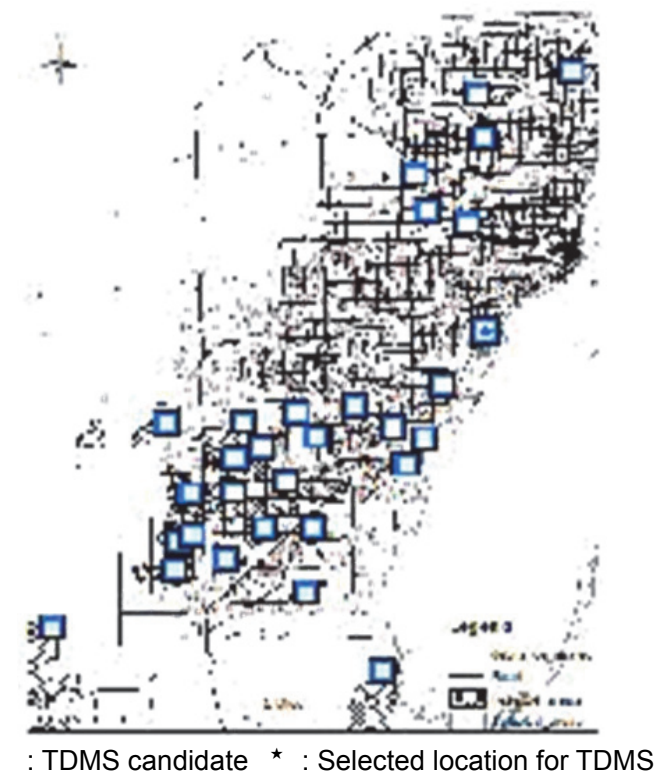

Figure 6. Recommended location for TDMS

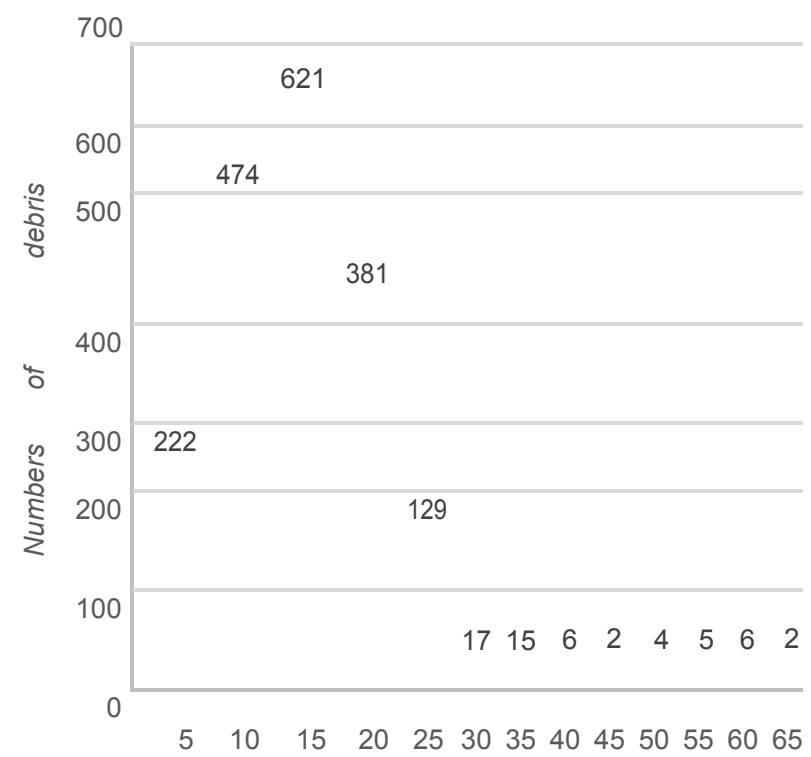

Figure 7. Numbers of debris within certain miles 


\section{EXPECTED RESULTS}

The TDMS selection model describes how location of TDMS would be selected by both geographical and optimization analysis. Through the geographical analysis, it automatically sorts out nonfeasible areas which are likely to have environmental damage in a community from a long-term perspective. It also visualizes feasible areas in a map for a location of TDMS to assist a decision maker.

Secondly, the TDMS selection model provides optimization analysis to select an appropriate location of TDMS. By the analysis, selected TDMS minimizes total hauling time from each debris collection points to TDMS within current road serviceability. Optimization analysis also provides distances from debris collection points to a selected TDMS. It enables a decision maker to decide required numbers of equipment to haul debris within certain working days. It enables a community to expedite debris removal and facilitate disaster management phases such as emergency response, recovery, and rebuilding.

Finally, the proposed TDMS selection model would be utilized to set up locations of TDMS in a debris management plan before disasters. In addition, it can be applied to any community that does not have preplanning for debris management. It enables a community to start operating debris removal as soon as possible while reducing potential risks, such as higher cost for debris removal or environmental damage to a community. Debris management teams would greatly benefit from the research for strategically siting TDMS for accelerating the debris removal process.

\section{REFERENCES}

Basnayake, B. F. A., Chiemchaisri, C., \& Visvanathan, C. (2006). Cleaning up after the tsunami in Sri Lanka and Thailand. Retrieved from http://www.waste-management-world.com/articles/ 2006/04/wastelands.html

Booth, W. (2010, March 7). Haiti faces colossal and costly cleanup before it can rebuild. Washington Post. Retrieved from http://www.washingtonpost. com/wp-dyn/content/article/2010/03/06/

AR2010030602544.html

Channell, M., Graves, M. R., Medina, V. F., Morrow, A. B., Brandon, D., \& Nestler, C. C. (2009, May). Enhanced tools and techniques to support debris management in disaster response missions (ERDC/EL TR-09-12). Vicksburg, MS: U.S. Army Corps of Engineers.

City of Lincoln. (2013). Solid waste plan 2040. Retrieved from http://lincoln.ne.gov/city/pworks/ waste/sldwaste/solidwasteplan2040/

Elias, V. (2013, June 26). Recovery field office completes mammoth New York debris removal mission. Retrieved from http://www.nan.usace. army.mil/Media/NewsStories/StoryArticleView/tabi d/5250/Article/15522/recovery-field-officecompletes-mammoth-new-york-debris-removalmission.aspx

Environmental Protection Agency. (1995). Planning for disaster debris (EPA530-K-95-010). Washington, D.C.: Environmental Protection Agency.

Environmental Protection Agency. (2008). Planning for natural disaster debris (EPA530-K-95-010). Washington, D.C.: Environmental Protection Agency.

Federal Emergency Management Agency. (2007). Debris management guide (FEMA-325). Washington, D.C.: Federal Emergency Management Agency.

Luther, L. (2006). Disaster debris removal after Hurricane Katrina: Status and associated issues. Washington, D.C.:Congressional Research Service.

Schaufelberger, J. E. (1999). Construction equipment management. Upper Saddle River, NJ: Prentice-Hall.

United Nations Environment Programme. (2008). Disaster waste management mechanism: $A$ practical guide for construction and demolition wastes in Indonesia. Nairobi, Kenya: United Nations Environment Programme. 